\section{RFID and ERP systems in supply chain management}

RFID and ERP systems in $\mathrm{SCM}$

\author{
Pejvak Oghazi
}

School of Social Sciences, Sodertorn University, Stockholm, Sweden

Fakhreddin Fakhrai Rad

Linnaeus University, Vaxjo, Sweden

Stefan Karlsson

Lund University, Lund, Sweden, and

Darek Haftor

Uppsala University, Uppsala, Sweden
Received 30 November 2016 Revised 22 August 2017 7 November 2017 Accepted 10 November 2017

\begin{abstract}
Purpose - The purpose of this paper is to identify the impact of enterprise systems (ESs), in particular radio frequency identification (RFID) and enterprise resource planning (ERP) systems, on supply chain management (SCM). The results of this conceptual paper demonstrate that ERP and RFID systems contribute to SCM by improving supply chain integration. Supply chain integration occurs to facilitate the flow of financing, products, and information throughout the chain. In this regard, ERP and RFID contribute to integration by enhancing the information flow across the supply chain.

Design/methodology/approach - This paper proposes a conceptual model developed from the findings of literature review within the research domains of SCM, ESs, and supply chain integration.

Findings - This conceptual study contributes to the existing theory by linking the concept of information technology, ESs to SCM. The conceptual model in this paper may provide insights for executives who wish to implement ERP or RFID systems in their businesses in order to achieve higher integration, both within internal sectors and also with supply chain partners.

Originality/value - The findings in this study contribute to the theory base by linking the concept of information technologies, ESs to SCM. The conceptual model presented in this paper can provide insights for executives who wish to implement ERP or RFID systems in their businesses in order to achieve higher integration within internal sectors and with supply chain partners. This study offers new understandings by investigating the impact of ERP and RFID together on SCM.
\end{abstract}

Keywords Enterprise resource planning (ERP), Supply chain management, Information technology,

Supply chain integration, Enterprise systems, Radio frequency identification (RFID)

Paper type Conceptual paper

\section{Introduction}

Since the early 1990s, global market competition has dramatically intensified (Oghazi, 2009). Globalization, continuous changes in customer demand, and technological breakthroughs have brought about calls for more comprehensive and updated business models and practices (Oghazi, 2009). In this regard, the application of information technology (IT) in business processes has the potential to offer new business opportunities for firms to move forward in the increasingly competitive global market (Oghazi, 2009). IT infrastructure enables organizations to exploit their competencies, contributing positively to their performance (Santhanam and Hartono, 2003; Bardhan et al., 2006).

(C) Pejvak Oghazi, Fakhreddin Fakhrai Rad, Stefan Karlsson and Darek Haftor. Published in the European Journal of Management and Business Economics. Published by Emerald Publishing Limited. This article is published under the Creative Commons Attribution (CC BY 4.0) licence. Anyone may reproduce, distribute, translate and create derivative works of this article (for both commercial and non-commercial purposes), subject to full attribution to the original publication and authors. The full terms of this licence may be seen at http://creativecommons.org/licences/by/4.0/legalcode

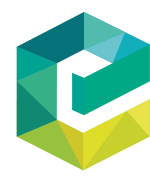

European Journal of Management and Business Economics Vol. 27 No. 2, 2018 pp. $171-182$ Emerald Publishing Limited $2444-8494$ DOI 10.1108/EJMBE-02-2018-0031 
EJMBE

27,2

In this context, enterprise systems (ESs) are considered to be one of the most significant subsets of IT to have arisen over the last two decades (Cotteleer and Bendoly, 2006). ESs are comprised of hardware and software that are aimed at standardization as well as integration of business processes and data being used across an organization (Davenport, 1998; Dorantes et al., 2013). Companies implement ESs in order to achieve higher efficiency (Oghazi, 2009). They may also adopt ESs because of external pressure in favor of adoption (Oghazi, 2009). In this regard, since the mid-1990s, US firms have increasingly invested in efforts to implement ESs into their organizational structure (Oghazi, 2009).

On the other hand, the nature of business competition has switched from rivalries among individual firms to the competition of supply chains. In other words, to achieve success in today's market, supply chains are competing against one another rather than individual organizations (Lee, 2005). Christopher (1998) asserts that supply chain management (SCM) includes the linkage of value-creating activities that occur downstream with upstream supply chain organizations in order to deliver higher product value to end customers. In this regard, breakthroughs within IT can potentially enable supply chains to develop stronger competitive advantages (Oghazi, 2009).

In line with this, $\mathrm{Li}$ (2012) argues that research pertaining to ESs as a subset of IT within the dimensions of SCM has been fragmented and is limited in scope. Research in this area is also incompatible, because the results often provide paradoxical answers in which some research supports the implementation of such systems, while other research opposes it (Oghazi, 2009). Based on this finding, the research question, which is designed to address this fragmentation in the literature, is as follows:

$R Q 1$. How can ESs, in particular radio frequency identification (RFID) and enterprise resource planning (ERP), enhance supply chain performance?

This paper strives to contribute to existing literature by presenting conceptual research that encompasses a comprehensive review which links the extant literature pertaining to SCM and ESs to supply chain performance.

To do so, according to the relevant logic of a conceptual paper, the definition of SCM and ESs will be presented in depth in Section 2. In the third section, the subsets of ESs and supply chain integration as a practice of SCM will be examined in detail. Also in Section 3, findings from the literature review regarding the impact of ESs on supply chain performance will also be identified. In Section 4, the conceptual model that links the results of the literature review will be discussed in detail. Finally, the research conclusions will be presented in Section 5.

\section{Definitions of concepts}

This section includes the definitions of SCM and ESs, which represent the primary concepts that form the basis of this research.

\subsection{ESs}

In the 1970s, scholars realized that some businesses had begun to attain a competitive advantage through the exploitation of IT systems by reducing their costs and increasing revenues (Oghazi, 2009). Following these findings, day-to-day development of the internet has gradually inserted IT into almost every aspect of our daily lives. In this context, businesses were no exception (Oghazi, 2009).

After 1995, when the internet had reached the requisite maturity to represent a trustworthy communications environment, various companies applied and utilized the internet protocol networking standard to homogenize and unify their heterogeneous, separated networks. These newly emerged IT infrastructures are called ESs (Mostaghel et al., 2012). These systems 
connect different hardware elements in computers as well as smaller networks, and as a result, a company-wide network is created that allows for the free movement of information across the organization (Davenport, 1998; Chandrashekar and Schary, 1999). ESs can also be designed in a manner that allows for inter-firm information flow (Davenport, 1998; Chandrashekar and Schary, 1999).

However, despite the overall positive view regarding the impact of ESs on businesses performance, implementation of such systems is often associated with high costs. Therefore, the strategic use of such systems plays an important role in maximizing the benefits of their usage (Oghazi, 2009). In this context, decision makers should make strategic decisions about different factors involved in the implementation of ESs. For instance, the deployment of advanced tracking systems enables a transportation firm to provide its customers with precise data. However, the managerial question is to what extent are customers willing to pay for highly accurate information, considering the fact that the deployment of such an advanced system is expensive (Levi et al., 2003; Oghazi, 2009).

There is no official index regarding those systems that are considered to be ESs (Oghazi, 2009). Nevertheless, a number of systems are often included within the division of ESs, including ERP, electronic data interchange, customer relationship management (CRM), product data interchange, and RFID (Vickery et al., 2003; Ramasubbu et al., 2008; Oghazi, 2009). For the purposes of this research, due to the research limitations, only RFID and ERP systems will be studied to investigate their impacts on supply chain performance.

\subsection{SCM}

Reductions in the life cycle of products, increases in the complexity of companies' joint ventures, and incremental needs for stronger customer service call for a comprehensive understanding of the exhaustive scope of SCM from the suppliers of very raw material to the final customers of the created product (Davis, 1993).

Since the early 1980s, various researchers (Oliver and Webber, 1982; Stevens, 1989; Handfield and Nichols, 2002) have studied the concept of SCM and its subdivisions. As part of this research effort, Bechtel and Jayaram (1997) divided the definition of SCM into four school of thoughts, which are as follows (Oghazi, 2009).

The functional chain awareness school. This perspective emphasizes the presence of functional areas that are joined together in order to facilitate the flow of material from the initial upstream supplier to the final customer (Oghazi, 2009). The major theme of this school is the physical flow of materials (Oghazi, 2009). In this school, definitions include all of the factors within the value-adding process, from the crude material to the utilization of the final product (Oghazi, 2009).

The linkage school. Definitions within this school focus primarily on the organizational boundaries that exist within a supply chain (Oghazi, 2009). This school emphasizes the legitimate linkage that exists between various chain actors (Turner, 1993; Lee and Larry, 2002). It seeks to explore how these linkages should be used to pave the way for the flow of materials across the supply chain with the purpose of balancing inventories and achieving a competitive advantage (Turner, 1993; Lee and Larry, 2002).

The information school. This school highlights the importance of the information flow throughout the chain (Oghazi, 2009). It emphasizes the unidirectional flow of information from customers to suppliers and the bidirectional flow from suppliers to customers (Oghazi, 2009). This school asserts that the information flow is the milestone of SCM (Oghazi, 2009). According to this perspective, information is not transferred from one chain actor to another, but rather, flows in the shape of feedback from customers regarding the performance of the supplier (Harrington, 1995; Towill, 1997). 
EJMBE

27,2

The integration/process school. The integration/process school encompasses the latest and most progressive definitions of SCM. It posits that SCM represents the integration of systems, including a set of processes that can deliver value to products for internal/ external customers (Oghazi, 2009). In other words, this perspective emphasizes the integration of value-creating processes across the chain. Customer satisfaction is the central concept of this school, which distinguishes this perspective from previous points of view (Oghazi, 2009). Followers of this school of thought are not limited to the specific network of the supply chain and are empowered to examine alternatives to the supply chain configuration (Oghazi, 2009). Such empowerment encourages the deletion of redundancies by allowing a set of activities to be performed simultaneously (Oghazi, 2009).

\section{Theories used in SCM and ESs}

This section will explain supply chain integration as a significant concept in the practice of SCM. It will also describe RFID and ERP systems as two scopes of ESs that are the focus of this paper, as previously discussed. Ultimately, this section will link the two aforementioned areas of concentration by investigating the impact of RFID and ERP on supply chain integration.

\subsection{Supply chain integration}

In today's global marketplace, firms should operate in a well-adjusted and integrated manner in order to sustain their competitive advantage, with the ultimate purpose of successfully marketing their goods and services (Oghazi, 2009). In this regard, firms that are working together within a supply chain strive to enhance their competitive performance through the integration of their internal processes as well as their internal functions, and, following this, through integration with upstream and downstream supply chain partners (i.e. suppliers, suppliers' suppliers, customers, etc.) (Wook Kim, 2006; Flynn et al., 2010; Wiengarten et al., 2016).

In order to understand how competitive capability and performance are sustained through supply chain integration, supply chain network structure is explained as follows. A supply chain network is comprised of a focal firm, which is usually the manufacturing company, its suppliers and suppliers' suppliers on the upstream tiers of the chain, as well as its customers and customers' customers on the downstream tiers of the chain (Oghazi et al., 2016). The number of downstream and upstream members of the chain varies depending on the specificities of the industry and the specific supply chain. A supply chain network illustrates the path that raw materials provided by suppliers follow in order to be transformed into the final product by manufacturers (Oghazi, 2009). This path continues with the storage and distribution of the final product by the distributer and the delivery to retailers before ultimately reaching final customers (Oghazi, 2009). The aforementioned path illustrates the flow of materials from upstream to downstream members of the network (Oghazi, 2009). In this context, if the final product that reaches the customer is returned, the product will follow the path from the downstream side of the network to the upstream side (Oghazi, 2009). For these reasons, the movement of products, information, and finances among the supply chain members takes place along both paths (Oghazi, 2009).

The flow of products, information, and finances among supply chain members requires strong integration between the chain actors to coordinate their activities and ensure the accurate flow of different loads. However, optimization of the supply chain configuration is a difficult task because of the very dynamic nature of supply chains and the inconsistent objectives of different partners in the chain (Oghazi et al., 2016). Nevertheless, prosperous companies (e.g. ABB and Tetra Pak) have proven the feasibility of optimal 
supply chain integration, as well as the potential benefits derived from such an integration, including enhancements in market share as well as overall financial performance (Levi et al., 2003).

Following the statements above, the focal companies in supply chains employ various integration strategies according to their integration level (Oghazi, 2009). Companies' integration levels are divided into four groups (Oghazi, 2009): internal integration; integration with suppliers to ensure the coordination of upstream activities and the accurate flow of loads (product, information, and finance flows) among upstream members; integration with customers to coordinate downstream activities to ensure the proper flow of loads among downstream members; and full integration to ensure the effective flow of products, information, and finances across the entire supply chain (Oghazi, 2009). These four integration levels will be discussed in more detail in Section 3.4 .

\section{$3.2 \mathrm{ERP}$}

When various enterprises encounter a number of independent information systems across organizations, they usually face large quantities of accumulated, non-standard information in different departments, functions, and business processes throughout the company that are not able to be transferred due to their heterogeneous formats (Oghazi, 2009). The inability to transfer various data across the organization often causes difficulties for managers in terms of monitoring and decision making due to the unavailability of sufficient valuable data (Oghazi, 2009). For this reason, various companies employ ERP systems to link information from different segments of the organization to one another, with the purposes of facilitating exact and on-time delivery, improving customer satisfaction, and reducing costs (Tsai et al., 2007; Häkkinen and Hilmola, 2008; Oghazi, 2009).

An ERP system consists of multiple modules that link information from different segments of the organization to one another. Each module (e.g. finance, logistic, order fulfillment, manufacturing) refers to a specific organizational function. Hence, by linking these modules to one another, data from different functions are interconnected and consequently provide managers with the required information in order to capture a bigger picture of the firm's operations and make more informed real-time decisions (Oghazi, 2009).

Moreover, an ERP system allows for the automation of business processes, which in turn can result in higher efficiency and lower costs for the firm (Oghazi, 2009). Nonetheless, it is important that firms review their processes before employing ERP systems, because automation of an ineffective and inefficient process means that the process will be consolidated and performed persistently, and it will be difficult to modify or replace after it has been automated (Oghazi, 2009).

\subsection{RFID}

RFID is a technology and physical infrastructure that is used as a tool to identify and label the objects (Oghazi, 2009). This technology encompasses a particular identifier that is transmitted from one device to the reader through radio waves within a preordained code definition (Oghazi, 2009). Characteristically, RFID includes a microprocessor that possesses informational memory space (Oghazi, 2009). Such a feature makes the RFID an important and functional tool for different means and purposes (Oghazi, 2009), One of which is SCM (Oghazi, 2009).

RFID allows for warehouse inventory management, ensuring that the shipped product conforms to the actual shipping order, preventing the stock-outs at the sales level, updating managers with the current phase of production, decreasing paperwork, enhancing the level 
EJMBE

27,2

of productivity, increasing the clarity of the product development process throughout the supply chain, decreasing the cost of labor, and rendering inventory forecasting more accurate (Srivastava, 2004; Shepard, 2005; Attaran, 2006; Markelevich and Bell, 2006; Lee et al., 2008; Oghazi, 2009). This technology allows for the tracking of every item that is tagged across the supply chain (Oghazi, 2009).

Despite the benefits of RFID, there are certain disadvantages correlated with this technology that must be tackled by firms. RFID tags include significant amounts of data that in some cases raise privacy concerns (Wu et al., 2006). In this context, an empirical study conducted by Günther and Spiekermann (2005) illustrates that 73 percent of 129 German customers would like RFID tags on purchased product to be removed at the checkout level due to customers' concerns regarding the data stored on the tags (Oghazi, 2009). In addition to privacy concerns, data stored on the tags do not follow a standard format that can be understood by different firms across the supply chain, which can lead to false data storage on the databases of partner firms (Wu et al., 2006; Oghazi, 2009).

\subsection{ERP and RFID in supply chain integration}

As briefly explained in Section 3.1, supply chain integration is divided into four levels that can be facilitated through ESs such as RFID and ERP.

First level of integration: internal integration. An organization that lacks any integration is often associated with separate departments that have little or no coordination with one another (Beheshti et al., 2014). In this regard, information is one of the necessary tools for successful transfer and movement throughout an organization in order to achieve higher coordination. Following this line of thought, Levi et al. (2003) assert that standard and accessible information within an organization contributes to a firm's ability to communicate and perform business in a timely manner, and at a lower cost.

In this context, the purpose of the internal integration of information throughout an organization is to connect separate systems that exist within various departments of an organization into one central information system and standardize the format of this shared information in order to make it understandable for all divisions within the organization (Oghazi, 2009). For this purpose, ERP systems provide the organization such an integration opportunity through bundles that are locate in different departments (Beheshti et al., 2014). These bundles collect the domestic data of every department and link them to the main database, which is accessible for use by all units within the organization. ERP systems also allow for the standardization of information, which enables the data to be used in different departments of the company.

Moreover, usage of RFID allows for the monitoring of materials/products as they move among different organizational divisions (Oghazi, 2009). Because RFID tags are capable of carrying information, the tagged product/material can be tracked at different locations. Through the ERP system, the data regarding these tagged products/materials can be transferred to other parts of the organization in order to provide various divisions with realtime information for better planning and control.

Second level of integration: integration with suppliers. Integration with suppliers includes the creation of win-win relationships with suppliers, which are associated with a strong commitment and trust. These are achieved gradually, in conjunction with attendant risks, data sharing, rewards, and long-term contracts (Vickery et al., 2003). In this regard, to achieve integration with suppliers through information sharing, ERP, and RFID systems can play vital roles. Possession of an ERP system by both manufacturing and supply companies, as well as the interconnection of these two ERP systems between these two supply chain partners, allow for a seamless informational infrastructure to exchange data between the two aforementioned chain partners. Through an ERP system, information 
regarding inventory level, number of orders, production rate, etc., can be accurately shared between the manufacturer and its supplier, at the right time, and at a low cost (Levi et al., 2003; Oghazi, 2009). This facilitation of information flow can lead to higher efficiency in the performance of business activities, higher customer satisfaction, and superior planning. In addition, RFID can be used to monitor the movement of supplies that are transferred to the manufacturer; it provides necessary information regarding what was being shipped and when it will be delivered.

Third level of integration: integration with customers. Relationships with customers are often characterized by asymmetrical power (Oghazi, 2009). Customers are aware that they are the ones who inject money into the chain, and their role in the entire supply chain is inevitable (Oghazi, 2009). This fact provides the customer with leverage to ask for more customized services (Oghazi, 2009). For this reason, integration with customers to increase their benefits is an important subject that must be comprehensively considered.

To accomplish this, many companies strive to enhance the quality of their relationships with customers (Oghazi, 2009). For this purpose, one of the main practices is CRM. CRM refers to the strategic capability and commitment of the company to meet its customers' demands (Lee and Billington, 1992; Powell, 1995). Firms can achieve stronger customer relationships by being more responsive to their customers' demands; following the creation of closer customer relationships, firms can be proactive in collecting data regarding customers' specific requirements and behaviors (Stroeken, 2001). Such closeness with customers makes it more difficult for competitors to truly compete (Vickery et al., 2003). In this regard, IT, including ERP systems, can facilitate better relationships with customers because it brings them closer to the firm through the provision of an effective mechanism that allows for information sharing between the customer and the supplier. Therefore, the inclusion of a module that addresses those factors involved with CRM in the main body of the ERP system can strengthen integration between the firm and its customers (Levi et al., 2003; Hatzithomas et al., 2007; Oghazi, 2009).

Furthermore, in B2B relationships, a customer that encompasses an RFID system can potentially obtain comprehensive product information from the tagged product delivered to them through the usage of RFID, which can also contribute to the integration between the supplying company and the customer.

Fourth level of integration: fully integrated supply chain. As previously discussed, finances, products, and information represent the loads that flow from upstream tiers of suppliers toward downstream tiers and vice versa (Oghazi, 2009). Therefore, supply chain integration occurs within the context of the three aforementioned load flows. For this purpose, Rai et al. (2006, p. 235) define information flow integration as "the extent to which operational, tactical, and strategic information is shared between a focal firm and its supply chain partners" (Oghazi, 2009). Operational information includes data such as inventory holdings, deliveries, and production schedules (Oghazi, 2009). Tactical information includes performance metrics, task implementation, and respective outcomes (Rai et al., 2006). Strategic information includes sales data (Rai et al., 2006; Stratman, 2007; Oghazi, 2009).

Based on the above statements, the integration of a supply chain's tactical, strategic, and operational information is vital in order to maximize the profitability for the entire chain of actors, as it is the general objective of SCM (Rai et al., 2006). For this purpose, IT, including RFID and ERP systems, can play a key role. Regarding the integration of operational information, RFID tags allow for the produced and delivered inventories to be tracked across the chain, and ERP allows this inventory-related information to be transmitted throughout the chain. Furthermore, strategic information that includes sales data can be accessed by all
RFID and ERP systems in $\mathrm{SCM}$ 
EJMBE 27,2

178

actors in the supply chain at different tiers through the use of the ERP system to avoid demand information falsification and to prevent the resulting bullwhip effect from occurring.

Effective sharing of information among the supply chain actors allows for production and delivery synchronization, better forecasting, coordination of inventory-related decisions, and the facilitation of a mutual understanding of performance bottlenecks (Rai et al., 2006). In this regard, IT, including RFID and ERP systems, can facilitate effective information sharing among supply chain members.

\section{Proposed conceptual model}

Based on the findings from the literature review, the conceptual model is proposed as in Figure 1.

Following the proposed conceptual model, it can be noted that ESs bridge the concept of SCM through the facilitation of supply chain integration. In this regard, supply chain integration takes place within the domain of four levels. Each level represents certain scope of integration that can be facilitated and enhanced through the use of IT, more specifically, through RFID and ERP systems.

At the first level, the ERP system and its bundles enhance the integration of information within an organization through the junction of independent information systems located in different divisions and departments into one central database. Through this system, various functions and activities can be implemented with proper coordination and harmony among different sectors in order to ensure effective and efficient performance. Such an integrated internal information system allows for top and divisional managers to make more informed and real-time decisions with respect to the overall condition that exists within the organization. An ERP system also homogenizes the data format throughout the organization to render the information more understandable and readable for every department. Following the facilitation of an intra-organizational information flow through an ERP system, RFID tags can also be a useful means to provide product-related data and to monitor product movement within the organization. Based on the declarations above, it can be said that RFID can potentially create the informational input for product status, and ERP can transmit this input across the organization.

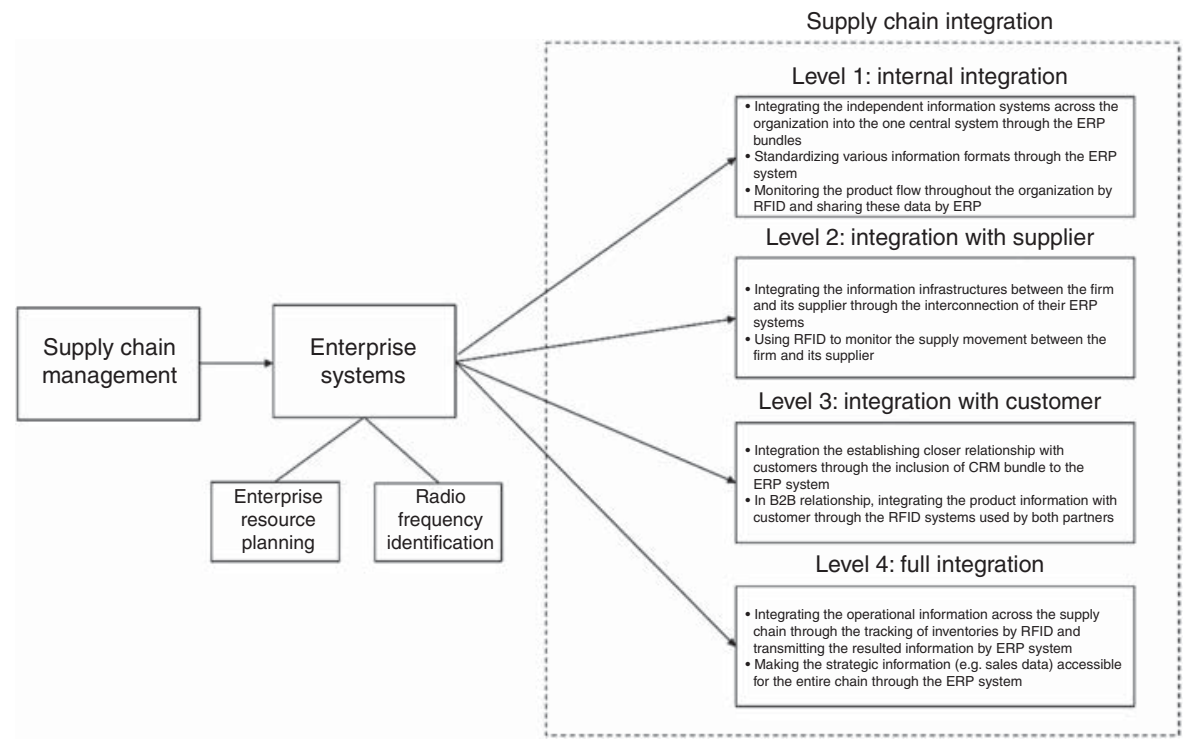

Figure 1.

Proposed conceptual model 
At the second level, RFID and ERP systems can facilitate the information flow in a manner that is similar to the first level, but within the context of the inter-organizational relationship between the firm (buyer) and its supplier. On one hand, RFID tags can inform companies regarding supply status (e.g. what is being shipping, its current location, where and when it will be delivered, etc.). On the other hand, these inputs provided by RFID can be transferred through the interconnection of the ERP system from the supply company to the buyer.

At the third level, an ERP system can enhance integration and relationships with customers through the CRM bundle, which provides the firm with access to comprehensive customer information to facilitate better understand and consequently offer customers products and services that match their requests and demands. In addition, within B2B relationships, RFID can improve integration with customers by enabling product information to be stored in microprocessors and delivered to customers in conjunction with the product to ensure the compatibility of delivered products with actual orders.

At the fourth level, the integration of operational information, such as inventory holding, delivery, and production schedules, can be enhanced among the entire supply chain of actors through the exploitation of ERP and RFID. As previously discussed, RFID can provide necessary information regarding inventory status, and supply chain members can have access to this information through seamlessly interconnected ERP systems. This allows for superior planning and the performance of tasks and activities more efficiently, and on time. ERP's ability to transmit information across the supply chain also allows for sales information to be precisely distributed among the chain's actors and, as a result, provide the opportunity for more accurate demand forecasting, which ultimately help to prevent the bullwhip effect from occurring.

\section{Concluding remarks}

Based on the findings above, it can be concluded that supply chain integration, which represents one of the major practices of SCM, can be enhanced through the use of ESs such as RFID and ERP. To be more specific, integration among the supply chain actors occurs in order to facilitate the effective and efficient flow of products, finances, and information across the supply chain for the purpose of maximizing profit for the entire network, which consists of suppliers, manufacturers, distributers, and customers. Accordingly, RFID and ERP, which represent the two ESs that are the focus of this study, can contribute to supply chain integration in terms of the flow of information. The two aforementioned forms of IT allow for the creation of an exchange mechanism that facilitates the accurate, on-time, and safe movement of information between members of the supply chain. This capability allows supply chain managers to have access to comprehensive information that gives them the ability to understand what is going on at different tiers of the supply chain. In summary, this capability provides them with a bigger picture of the activities taking place throughout the chain. Such an opportunity aids managers in making more informed decisions, with enhanced planning and control of processes and activities.

Moreover, despite the benefits of ESs, their implementation is often associated with high costs. Therefore, it is critically important that prior to system implementation, firms conduct deep analyses regarding their internal processes as well as their overall situation with respect to the external environment in order to prevent the waste that can result from ES implementation failure.

Furthermore, due to the limitations of this study, its explicit focus is on ERP and RFID systems in particular. In view of this limitation, it is recommended that other scholars should perform future to identify the impact of other ESs on SCM to provide further clarification in this fragmented field of study. 
EJMBE

27,2

180

\section{References}

Attaran, M. (2006), "RFID pays off: real benefits begin to accrue in several industries", Industrial Engineer, Vol. 38 No. 9, pp. 46-51.

Bardhan, I., Whitaker, J. and Mithas, S. (2006), "Information technology, production process outsourcing, and manufacturing plant performance", Journal of Management Information Systems, Vol. 23 No. 2, pp. 13-40.

Bechtel, C. and Jayaram, J. (1997), "Supply chain management: a strategic perspective", The International Journal of Logistics Management, Vol. 8 No. 1, pp. 15-34.

Beheshti, H.M., Oghazi, P., Mostaghel, R. and Hultman, M. (2014), "Supply chain integration and firm performance: an empirical study of Swedish manufacturing firms", Competitiveness Review, Vol. 24 No. 1, pp. 20-31.

Chandrashekar, A. and Schary, P.B. (1999), "Toward the virtual supply chain: the convergence of IT and organization", The International Journal of Logistics Management, Vol. 10 No. 2, pp. $27-40$.

Christopher, M. (1998), "Logistics and supply chain management: strategies for reducing cost and improving service", Financial Times/prentice Hall, London.

Cotteleer, M.J. and Bendoly, E. (2006), "Order lead-time improvement following enterprise information technology implementation: an empirical study”, MIS Quarterly, Vol. 30 No. 3, pp. 643-660.

Davenport, T.H. (1998), "Putting the enterprise into the enterprise system", Harvard Business Review, Vol. 76 No. 4, pp. 121-131.

Davis, T. (1993), "Effective supply chain management", Sloan Management Review, Vol. 34 No. 4, pp. 35-46.

Dorantes, C.A., Li, C., Peters, G.F. and Richardson, V.J. (2013), "The effect of enterprise systems implementation on the firm information environment", Contemporary Accounting Research, Vol. 30 No. 4, pp. 1427-1461.

Flynn, B.B., Huo, B. and Zhao, X. (2010), "The impact of supply chain integration on performance: a contingency and configuration approach", Journal of Operations Management, Vol. 28 No. 1, pp. 58-71.

Günther, O. and Spiekermann, S. (2005), "RFID and the perception of control: the consumer's view", Communications of the ACM, Vol. 48 No. 9, pp. 73-76.

Häkkinen, L. and Hilmola, O.P. (2008), "ERP evaluation during the shakedown phase: lessons from an after-sales division”, Information Systems Journal, Vol. 18 No. 1, pp. 73-100.

Handfield, R.B. and Nichols, E.L. (2002), Supply Chain Redesign: Transforming Supply Chains Into Integrated Value Systems, FT Press, NJ.

Harrington, L. (1995), "Logistics, agent for change: shaping the integrated supply chain", Transportation and Distribution Management, Vol. 36 No. 1, pp. 30-34.

Hatzithomas, L., Stamelos, I., Fotiadis, T. and Mylonakis, J. (2007), "Quality and effectiveness of enterprise resource planning-customer relationship management systems: implications for information systems marketing strategies", Journal of Applied Business Research, Vol. 23 No. 3, p. 33.

Lee, H.L. and Billington, C. (1992), "Managing supply chain inventory: pitfalls and opportunities", Sloan Management Review, Vol. 33 No. 3, pp. 65-73.

Lee, J.K. and Larry, P.R. (2002), Operations Management: Strategy and Analysis, 6th ed., Pearson College Division, NJ.

Lee, L.S., Fiedler, K.D. and Smith, J.S. (2008), "Radio frequency identification (RFID) implementation in the service sector: a customer-facing diffusion model", International Journal of Production Economics, Vol. 112 No. 2, pp. 587-600.

Lee, W. (2005), “A joint economic lot size model for raw material ordering, manufacturing setup, and finished goods delivering", Omega, Vol. 33 No. 2, pp. 163-174. 
Levi, D.S., Kaminsky, P. and Levi, E.S. (2003), Designing and Managing the Supply Chain: Concepts, RFID and ERP Strategies, and Case Studies, McGraw-Hill, New York, NY.

Li, L. (2012), "Effects of enterprise technology on supply chain collaboration: analysis of China-linked supply chain”, Enterprise Information Systems, Vol. 6 No. 1, pp. 55-77.

Markelevich, A. and Bell, R. (2006), "RFID: the changes it will bring", Strategic Finance Magazine, Vol. 88 No. 2, pp. 46-49.

Mostaghel, R., Oghazi, P., Beheshti, H.M. and Hultman, M. (2012), "Adoption of enterprise systems and radio frequency identification among service firms", The Service Industries Journal, Vol. 32 No. 15 , pp. 2435-2443.

Oghazi, P. (2009), "Supply chain management: an empirical study on Swedish manufacturing firms' enterprise systems adoption, supply chain integration, competition capability and performance", doctoral dissertation, Luleå tekniska universitet.

Oghazi, P., Rad, F.F., Zaefarian, G., Beheshti, H.M. and Mortazavi, S. (2016), "Unity is strength: a study of supplier relationship management integration”, Journal of Business Research, Vol. 69 No. 11, pp. 4804-4810.

Oliver, R.K. and Webber, M.D. (1982), "Supply-chain management: logistics catches up with strategy", Outlook, Vol. 5 No. 1, pp. 42-47.

Powell, T.C. (1995), “Total quality management as competitive advantage: a review and empirical study", Strategic Management Journal, Vol. 16 No. 1, pp. 15-37.

Rai, A., Patnayakuni, R. and Seth, N. (2006), "Firm performance impacts of digitally enabled supply chain integration capabilities", MIS Quarterly, Vol. 30 No. 2, pp. 225-246.

Ramasubbu, N., Mithas, S. and Krishnan, M.S. (2008), "High tech, high touch: the effect of employee skills and customer heterogeneity on customer satisfaction with enterprise system support services", Decision Support Systems, Vol. 44 No. 2, pp. 509-523.

Santhanam, R. and Hartono, E. (2003), "Issue in linking information technology capability to firm performance", MIS Quarterly, Vol. 27 No. 1, pp. 125-153.

Shepard, S. (2005), RFID: Radio Frequency Identification, McGraw Hill, New York, NY.

Srivastava, B. (2004), "Radio frequency ID technology: the next revolution in SCM", Business Horizons, Vol. 47 No. 6, pp. 60-68.

Stevens, G.C. (1989), "Integrating the supply chain", International Journal of Physical Distribution \& Materials Management, Vol. 19 No. 8, pp. 3-8.

Stratman, J.K. (2007), "Realizing benefits from enterprise resource planning: does strategic focus matter?", Production and Operations Management, Vol. 16 No. 2, pp. 203-216.

Stroeken, J.H. (2001), "Information technology, innovation and supply chain structure", International Journal of Services Technology and Management, Vol. 2 Nos 3/4, pp. 269-288.

Towill, D.R. (1997), "The seamless supply chain-the predator's strategic advantage”, International Journal of Technology Management, Vol. 13 No. 1, pp. 37-56.

Tsai, W.H., Fan, Y.W., Leu, J.D., Chou, L.W. and Yang, C.C. (2007), "The relationship between implementation variables and performance improvement of ERP systems", International Journal of Technology Management, Vol. 38 No. 4, pp. 350-373.

Turner, J.R. (1993), "Integrated supply chain management - what's wrong with this picture?", Industrial Engineering, Vol. 25 No. 12, pp. 52-55.

Vickery, S.K., Jayaram, J., Droge, C. and Calantone, R. (2003), "The effects of an integrative supply chain strategy on customer service and financial performance: an analysis of direct versus indirect relationships", Journal of Operations Management, Vol. 21 No. 5, pp. 523-539.

Wiengarten, F., Humphreys, P., Gimenez, C. and McIvor, R. (2016), "Risk, risk management practices, and the success of supply chain integration", International Journal of Production Economics, Vol. 171 No. 3, pp. 361-370. 
EJMBE

27,2

182
Wook Kim, S. (2006), "The effect of supply chain integration on the alignment between corporate competitive capability and supply chain operational capability", International Journal of Operations \& Production Management, Vol. 26 No. 10, pp. 1084-1107.

Wu, N.C., Nystrom, M.A., Lin, T.R. and Yu, H.C. (2006), "Challenges to global RFID adoption", Technovation, Vol. 26 No. 12, pp. 1317-1323.

\section{Further reading}

Ellram, L.M. and Cooper, M.C. (2014), "Supply chain management: it's all about the journey, not the destination”, Journal of Supply Chain Management, Vol. 50 No. 1, pp. 8-20.

\section{Corresponding author}

Pejvak Oghazi can be contacted at: pejvak.oghazi@sh.se 